\title{
A Rare Confusing Nevus Variant: Meyerson Nevus
}

\section{Pelin YILDIZ', Özlem Su KÜÇÜK², Zeynep TOSUNER', Belfin Nur ARICI², Didem DIZMAN², Uğur DEVECI ${ }^{4}$, Cuyan DEMIRKESEN ${ }^{5}$ \\ ${ }^{1}$ Department of Pathology, Bezmialem Vakif University School of Medicine, İstanbul, Turkey \\ ${ }^{2}$ Department of Dermatology, Bezmialem Vakif University School of Medicine, İstanbul, Turkey \\ ${ }^{3}$ Istanbul Community Health Center, İstanbul, Turkey \\ ${ }^{4}$ Department of General Surgery, Maltepe University School of Medicine, İstanbul, Turkey \\ ${ }^{5}$ Department of Pathology, Accbadem University School of Medicine, İstanbul, Turkey}

\section{ABSTRACT}

Meyerson nevus is a rare benign entity described by Meyerson et al in 1971 as a melanocytic nevus surrounded by inflammatory, eczematous eruption that resolves spontaneously or by topical steriod therapy (fluticasone propionate, Abdi İbrahim İlaç San. ve Tic. A.Ş., İstanbul), but the nevus persists. This entity is not well known and there is limited information in the literature. Since the lesion may develop suspicion for malignancy, it is important to keep this entity in mind. In this article we present three Meyerson nevi, two of which belong to one patient.

Keywords: Meyerson, nevus, rare, variant

\section{Introduction}

Meyerson nevus is described as a melanocytic nevus surrounded by inflammatory, eczematous eruption, and was first described by Meyerson in 1971 (1). In this article, two patients with melanocytic nevi surrounded by eczema, characterized by histologic features of parakeratosis, spongiosis, acanthosis in the epidermis and perivascular lymphocytic infiltrate within the dermis, were described. Topical steroid therapy succeeded to resolve the lesion leaving a slight hypopigmentation around the unchanged nevi $(2,3)$.

Since then, not only pigmented (junctional nevi, Sutton nevi, atypical nevi, and congenital nevi) but also non-melanocytic lesions (basal cell carcinomas, spinocellular carcinomas, seborrheic keratosis, keloids, dermatofibromas, and insect bites) were documented with the findings of eczematization (3).

This entity of eczematization of the centrally located nevi/lesion is called as Meyerson phenomenon (halo dermatitis) (4-6).

Here we report three cases of Meyerson nevus, two of which were seen in the same person.

\section{Case Reports}

\section{Case 1}

A 23-year-old woman with atopic dermatitis presented with a $0.4 \mathrm{~cm}$ pigmented, kserotic, itchy lesion on her groin. Two months later she attended to dermatology clinic with another excoriated lesion on her chest. In dermoscopic examination, (Fotofinder systems, Bayern, Germany) both lesions had irregular borders with a negative pigmented network and some

Cite this article as: Yıldız P, Küçük ÖS, Tosuner Z, Arıcı BN, Dizman D, Deveci U. A Rare Confusing Nevus Variant: Meyerson Nevus. Bezmialem Science 2018; 6: 80-2.

This study was presented at the $24^{\text {th }}$ National Pathology Congreess (2014 Trabzon, Turkey)

Address for Correspondence: Pelin YILDIZ, Bezmialem Vakıf Üniversitesi Tıp Fakültesi, Patoloji Anabilim Dall, İstanbul, 
blue-gray areas reminiscent of regression on an erythematous background. Pigmented globules were detected at the periphery (Figure 1). The lesions were excised with a prediagnosis of dysplastic nevi. Histopathological examination revealed lentiginous hyperplasia, containing some small melanocytic nests at the dermoepidermal junction. Some nests at the tips of rete ridges had a bridging tendency. Due to excoriation, nuclear fragments and plasma exudation were seen on the surface. Remarkable feature was diffuse lymphohistiocytic infiltrate in the upper dermis (Figure 2). Additionally, prominent spongiosis (Figure 3) and few eosinophils were noted within the epidermis.

Both lesions were diagnosed as eczematous lentiginous nevus with Meyerson phenomenon (Meyerson nevus).

\section{Case 2}

The second patient was a 51-year-old man, presenting with a $0.7 \mathrm{~cm}$ pigmented lesion on his lumbar region. Since the lesion was suspicious for malignancy, it was excised. The patient had similar microscopic features with the former patient such as prominent spongiosis, eosinophilic spongiosis in the epidermis, and perivascular lymphocytic infiltration. Furthermore melanocytic nests were detected in the dermis.

This lesion was reported as eczematous compound dysplastic nevus (Meyerson nevus).

\section{Discussion}

Meyerson nevus is a rare entity, described as a symmetrical erythema and scale over or around centrally localized melanocytic nevus due to eczemation. Occasional cases with atopic dermatitis have been reported (4). Our first patient had some features of atopy such as eczematous dermatitis, xerosis, and pruritus, from her childhood.

Broadly, immediate change of size and loss of symmetry could raise the suspicion for malignancy. Under these circumstances, dermoscopic appearance of the Meyerson nevus could be challenging. Also, on microscopic evaluation, diffuse inflammatory reaction could be alarming. Although coexistence with malignancy was described (1), even benign nevus could raise suspicion for malignancy as in our second patient. It is important to separate this benign condition from malignant tumors with inflammation.

The findings of eczematization resolve in time and need no therapy, but underlying lesion persists. Topical steroids and surgical excision are the choices for the therapy $(4,7)$.

The nevi were resected with free margins. No complaint or recurrence was stated after the excision.

Meyerson postulated pityriasis rosea as the cause of eruption, but it is unclear. Some other triggering factors were suggested as ultraviolet radiation, chemotherapy, alpha-2B interferon therapy for HCV and Behçet's disease $(2,6)$.
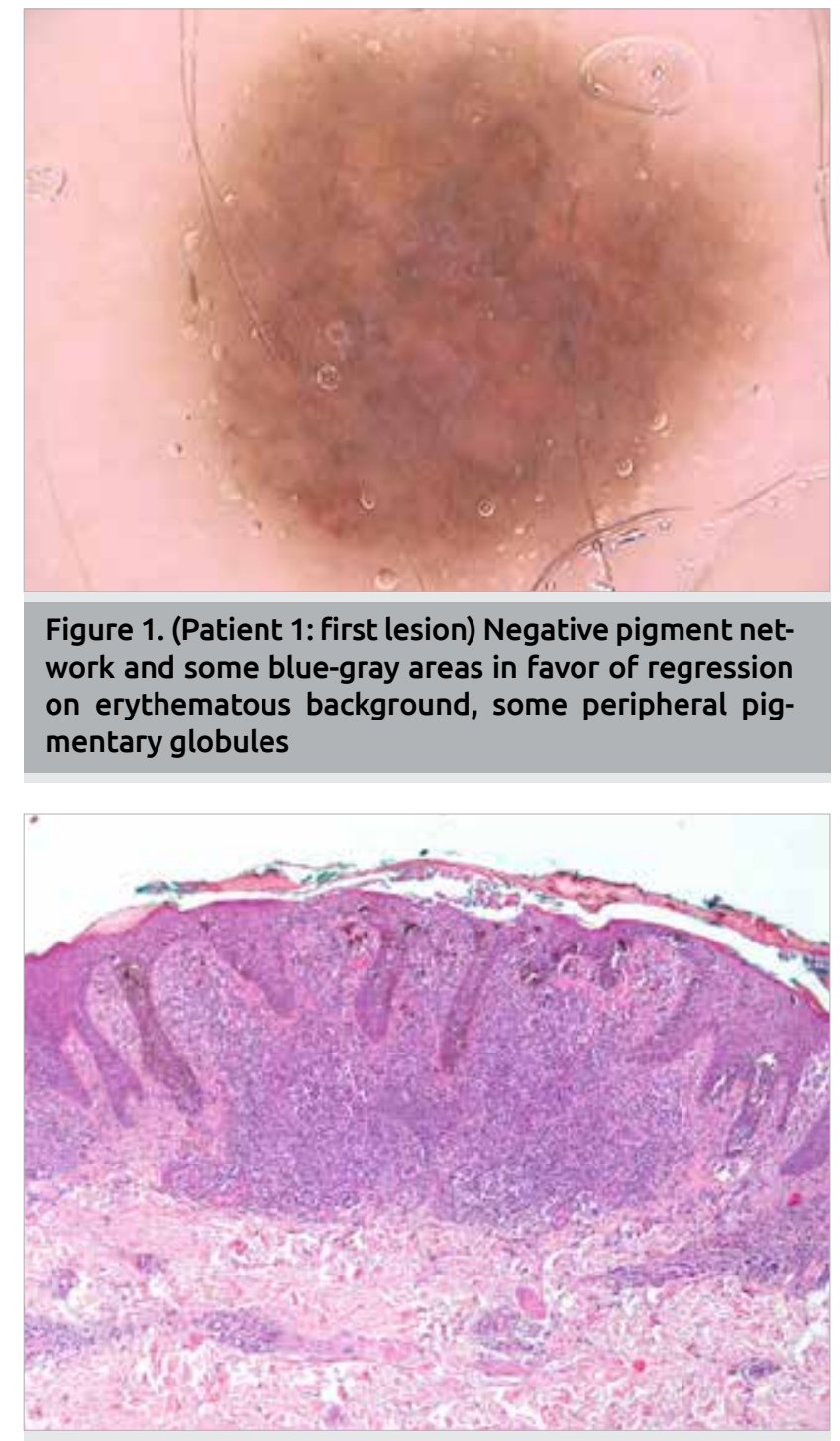

Figure 2. (Patient 1: first lesion) Marked excoriation and eczematization, incresed pigmentation, diffuse lymphohistiocytic infiltrate in the upper dermis (HEx40)

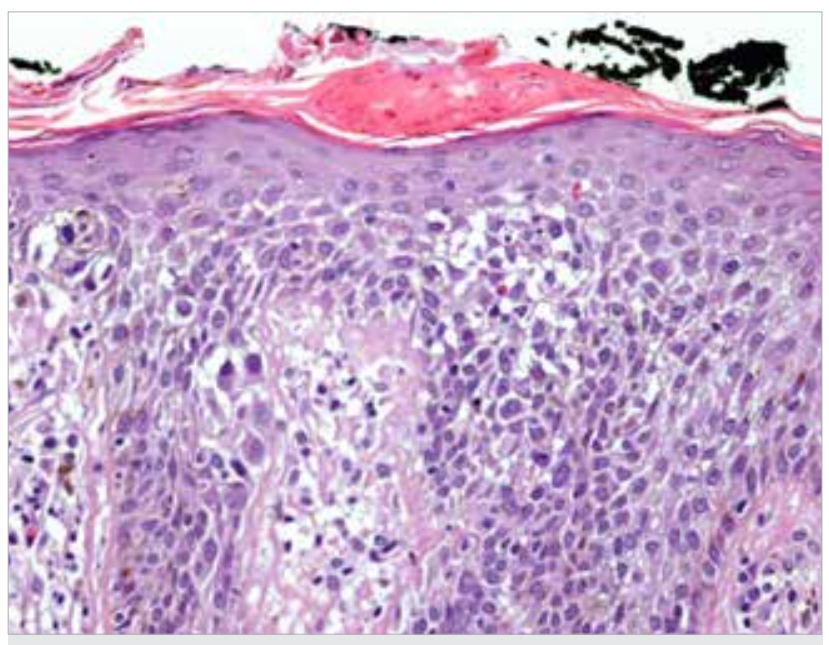

Figure 3. (Patient 1: first lesion) Spongiosis, eosinophilic spongiosis, and melanocytic nests in the epidermis (HEX200) 
Halo (Sutton) nevus should be considered in the differential diagnosis. It is usually a pigmented lesion, sometimes a neuroid nevus, a blue nevus, a neurofibroma, or a primary or secondary malignant melanoma, surrounded by a halo of depigmented zone. Depigmented zone had no clinical signs of inflammation. In the original descriptions, Meyerson nevus had neither regression nor depigmentation of the central lesion $(8-10)$.

\section{Conclusion}

Meyerson nevus is a rare benign entity. It is not well known and there is limited information in the literature. Since, the lesion might develop suspicion for malignancy, like in our patients, it is important to keep this entity in mind. More patients and long follow up could help to clarify the pathogenesis of Meyerson nevus and association between the other lesions.

Informed Consent: Written informed, consent was obtained from patient who participated in this case.

Peer-review: Externally peer-reviewed.

Author Contributions: Concept - P.Y., Ö.S.K., C.D.; Design - P.Y., Z.T., D.D.; Supervision - P.Y., Ö.S.K., C.D.; Resource - B.N.A., U.D., P.Y.; Materials - Ö.S.K., D.D., P.Y.; Data Collection and/or Processing - P.Y., D.D., B.N.A., U.D.; Analysis and/or Interpretation - P.Y., Z.T., C.D.; Literature Search - P.Y., Z.T.; Writing - P.Y., C.D., Ö.S.K., Z.T.; Critical Reviews - C.D., Ö.S.K.

Conflict of Interest: No conflict of interest was declared by the authors.
Financial Disclosure: The authors declared that this study has received no financial support.

\section{References}

1. Meyerson LB. A peculiar papulosquamous eruption involving pigmented nevi. Arch Dermatol 1971; 103: 510-2. [CrossRef]

2. Fernandez-Flores A. Eponyms, morphology, and pathogenesis of some less mentioned types of melanocytic nevi. Am J Dermatopathol 2012; 34: 607-18. [CrossRef]

3. Gabbi TV, Omar ED, Criado PR, Valente NY, Martins JE. Clinical, dermoscopic and histopathological evaluation of the Meyerson nevus: case report. An Bras Dermatol 2010; 85: 6813. [CrossRef]

4. Rolland S, Kokta V, Marcoux D. Meyerson phenomenon in children: observation in five cases of congenital melanocytic nevi. Pediatr Dermatol 2009; 26: 292-7. [CrossRef]

5. Simon V, Hartschuh W, Flux K. Meyerson-Phenomenon hides a nevus flammeus. J Dtsch Dermatol Ges 2011; 9: 305-7. [CrossRef]

6. Schofield C, Weedon D, Kumar S. Dermatofibroma and halo dermatitis. Australas J Dermatol 2012; 53: 145-7. [CrossRef]

7. Schepis C, Siragusa M. The Meyerson phenomenon in a teenager. Dermatol Online J 2008; 14: 28.

8. Rodins K, Byrom L, Muir J. Early melanoma with halo eczema (Meyerson's phenomenon). Australas J Dermatol 2011; 52: 703. [CrossRef]

9. Weedon D, Farnsworth J. Spongiotic changes in melanocytic nevi. Am J Dermatopathol 1984; 6(Suppl): 257-9.

10. Kus S, Ince U, Candan I, Gurunluoglu R. Meyerson phenomenon associated with dysplastic compoundnevi. J Eur Acad Dermatol Venereol 2006; 20: 350-1. [CrossRef] 